\title{
VENTILAÇÃO ARTIFICIAL COM O AUXÍLIO DE RESPIRADOR BIRD-MARK 7
}

\author{
Zuleika M. Kannebley *
}

\section{INTRODUÇĀO}

Frequentemente encontramos nas enfermarias do Hospital das Clínicas da Faculdade de Medicina da U.S.P. o respirador Bird sendo usado para pacientes com problemas pulmonares originados de circunstâncias as mais diversas. Ora são pacientes em pós operatório imediato de cirurgia torácica, ora são pacientes com traumatismo de tórax ou politraumatizados, ou ainda são pacientes portadores de moléstias neurológicas. Desde que nestas situações o cuidado de enfermagem inclui também a observação do funcionamento e conservação do aparelho, assim como as reações do paciente durante o tratamento, com o intuito de sempre melhorar a qualidade de nossa assistência, temos procurado nos esclarecer sobre o que é realmente o respirador Bird, seus objetivos e seu funcionamento.

\section{Insuficiência Respiratória}

Insuficiência respiratória é a manifestação clínica de várias condições patológicas que se caracterizam por uma deficiência dos pulmōes em realizar uma ventilação normal, podendo esta falha estar relacionada tanto com o fornecimento de oxigênio ao sangue arterial como com a eliminação do gás carbônico. Uma ventilação deficiente, ainda que me grau incipiente, deverá ser combatida pelo emprego de medidas eficazes antes que o acúmulo progressivo de $\mathrm{CO}_{2}$ transforme o quadro inicial em insuficiência respiratória aguda que é acompanhada de uma acidose respiratória.

* Professôra de Enfermagem Cirúrgica da Escola de Enfermagem da USP. Artigo transcrito da Rev. da Esc. de Enf. da USP. 2 (2): set. 1968. 
Os estudos já feitos sobre a Bioquímica do sangue nos esclarecem sobre o mecanismo pelo qual se instala a acidose respiratória. $\mathrm{O}$ pH do sangue, cujo valor normal é 7.4 (ligeiramente alcalino), é regulado pela relação entre bicarbonato $\left(\mathrm{Na} \mathrm{HCO}_{3}\right)$ e ácido carbônico $\left(\mathrm{H}_{2} \mathrm{CO}_{3}\right)$ relação esta indicada pela seguinte proporção:

$$
\frac{\mathrm{Na} \mathrm{HCO}_{3}}{\mathrm{H}_{2} \mathrm{CO}_{3}}=\frac{20}{1},
$$

entenda-se que no sangue aquela relação é de 20 partes de bicarbonato para uma de ácido carbônico. A retenção do $\mathbf{C O}_{2}$ provoca o aumento do $\mathrm{H}_{2} \mathrm{CO}_{3}$ de acordo com a reação $\mathrm{H}_{2} \mathrm{CO}_{3} \quad \mathrm{HO}-$ $\mathbf{C O}_{2}$. Portanto, o aumento do $\mathbf{C O}_{2}$, aumentando o denominador da proporção acima, alterra também a relação bicarbonato e ácido carbônico fazendo baixar o pH sanguíneo que passará de alcalino para ácido. O organismo humano tolera e reage bem às pequenas variações do $\mathrm{pH}$, porém, alteraçōes mais pronunciadas repercutem desfavoravelmente e são incompatíveis com a vida.

$\mathrm{Na}$ insuficiência respiratória aguda, a ventilação deficiente, permitindo o acúmulo de $\mathbf{C O}_{2}$, favorece a instalação de um quarto de acidose respiratória pelo mecanismo acima descrito.

Entre as causas responsáveis por ventilação deficiente são citados:

a) doenças pulmonares que oferecem uma obstrução interna à passagem do ar: enfisema, fibroses, crise asmática rebelde;

b) depressão central por intoxicação com drogas;

c) doenças neurológicas tais como a poliomielite, polirradiculoneurite, mielite, encefalite, tétano;

d) doença muscular: miastenia grave;

e) traumatismos do tórax com esmagamento da parede;

f) obstrução das vias aéreas superiores: corpos estranhos, difteria;

g) cirurgia torácica e abdominal alta.

Todas essas causas são processos que levam a uma alteração da mecânica respiratória a qual evolui permitindo o aprecimento da insuficiência ventilatória cujo quadro clínico se manifesta por alguns do seguintes sintomas: agitação, taquicardia, dspnéia, tosse, hipersecreção, espasmo brônquico e cianose.

As dosagens laboratoriais de $\mathrm{CO}_{2}$ e $\mathrm{O}_{2}$ no sangue arterial e da concentração de ions de hidrogênio revelada pelo $\mathrm{pH}$ sanguíneo são exames que ajudarão o médico na avaliação do grau da insuficiência. 


\section{Ventilação Pulmonar}

Entende-se por ventilação pulmonar ao intercâmbio de gases ao nível dos alvéolos pulmonares. Ela envolve portanto a entrada e saída de ar nos pulmões e as trocas gasosas entre pulmōes e o ambiente.

De acordo com suas exigências metabólicas, os adultos normais respiram de 5 a 10 litros de ar por minuto.

Os fatores que controlam a ventilação pulmonar são: frequência respiratória e volume corrente. O produto desses fatores expresso em litros corresponde ao valor da ventilação por minuto. Portanto se uma pessoa tem 12 respirações por minuto e um volume corrente de $500 \mathrm{ml}$, a sua ventilação pulmonar por minuto será:

$12 \times 500 \mathrm{ml}=6$ litros.

Volume corrente é o volume de ar inspirado ou expirado em cada respiração e seu valor normal varia de 550 a $600 \mathrm{ml}$ em indivíduo normal do sexo masculino.

\section{Tipos de respiradores}

A terapêutica da insuficiência respiratória conta atualmente com vários aparelhos mecânicos de ventilação artificial, e em nosso meio hospitalar, frequentemente, as enfermeiras têm sob seus cuidados pacientes aos quais foi aplicada aquela terapêtica de sustentação. $O$ auxílio mecânico não elimina outros cuidados importantes tais como: desobstrução das vias aéreas, tratamento da infecção, da secreção brônquica, do trauma, do envenenamento, do espasmo brônquico. Os respiradores mecânicos são usados quando os recursos terapêuticos adotados inicialmente (limpeza das vias aéreas, oxigenação ou outras medidas) são insuficientes para restabelecer a ventilação normal do paciente, ou quando a presença de anormalidades da caixa toráxica (músculos ou costelas) ou da função pulmonar constituem um obstáculo à passagem do ar. Nestas situações o paciente não consegue abastecer de oxigênio e eliminar dos tecidos o dióxido de carbono; o emprego de um respirador mecânico virá auxiliá-lo a superar a dificuldade respiratória.

Há vários tipos e respiradores e todos eles têm a função de fazer o trabalho da respiração forçando a entrada de ar nos pulmões.

Para classificar os numerosos tipos de respiradores, Mushin e seus colaboradores (cit por Saraiva7) adotam como critério essencial a mudança da fase da inpiração para a expiração o que permite classificá-los em apenas três grupos:
a) ciclados por tempo
b) ciclados por volume
c) ciclados por pressão 
Desta forma, tanto os respiradores que atuam por pressão aplicada externamente ao tórax (tanques, pulmões de aço, couraças. camas basculantes) como aqueles que atuam por pressão aplicada diretamente à traquéia ( ${ }^{*} \mathrm{RPPI}$ ou ${ }^{* *}$ RPPIN) podem ser enquadrados em um dos três grupos acima mencionados.

Contamos com uma grande variedade de respiradores mecânicos e a decisão do médico na escolha o melhor tipo é tarefa difícil, pois cada um deles apresenta uma desvantagem peculiar. Entretanto, em ventilação mecânica, o sucesso do tratamento depende muito mais da "Pessoa" ou das "Pessoas" responsáveis pelo doente e pela máquina do que propriamente do tipo de aparelho. O conhecimento que se deve ter sobre a máquina, a supervisão constante a observância rigorosa dos cuidados essenciais são exigências básicas para se garantir uma ventilação adequada para cada caso em particular.

\section{O Respirador Bird-Mark 7}

A Bird Corporation tem fabricado vários tipos de respiradores, razão pela qual encontramos nossos pacientes no hospital, sendo assistidos ora por um Bird-Mark 7, ora por um Bird-Mark 8. Embora de números diferentes (7 e 8), os dois são semelhantes sendo. que o Bird-8 possui a mais, um gerador de pressão negativa para a fase de expiração, e dependendo do critério médico e das condiçōes do paciente, poderá ou não ser colocado em atividade.

$\mathrm{Na}$ exposição que apresentamos a seguir focalizaremos especificamente um Bird-Mark 7, porém, o que for abordado aplica-se também ao Bird-Mark 8.

O ventilador Bird-Míark 7, ciclado por pressão, é um aparelho de pressão positiva intermitente que permite que se faça sob pressão positiva a introdução de ar ou $\mathrm{O}_{2}$ nos pulmões durante a fase da inspiração. A pressão negativa que normalmente existe num tórax distendido durante a inspiração, será substituída pela pressão positiva originada no aparelho. Isto contribui para ajudar a vencer a resistência ao fluxo de gás e à dilatação dos bronquíolos.

Com ele pode-se fazer tanto a ventilação assistida como a automática. Quando o paciente não apresenta paralisia dos movimentos respiratórios poderá ser beneficiado por uma ventilação assistida e neste caso o aparelho irá complementar uma respiração deficiente; um esforço mínimo e controlável do paciente será suficiente para desencadear o ciclo respiratório. A ventilação automática aplica-se ao paciente em apnéia ou quando se deseja respiração controlada.

* RPPI: Respiração por pressão positiva intermitente.

** RPPNI: Respiração por pressão positiva e negativa intermitentes. 
Quando a ventilação artificial é usada durante periodos longas de tratamento, uma traqueostomia praticada previamente na paciente, servirá à adaptação do aparelho às vias aelreas, e tratando-se de periodos curtos pode-se, com o mesmo objetivo, usar a intubação endotraqueal ou ainda máscaras apropriadas. Nos casos de traqueostomias em adultos são usadas as cânulas com balão de vedação (cuff) e para crianças as cânulas simples. A desinsuflação peroidica do balão de vedação é um cuidado importante para prevenir escaras na traquéia.

A fim de manter os brônquios e a traquéia convenientemente úmidos, um nebulizador contendo água estéril ou sôro fisiológico e intercalado no circuito entre aparelho e paciente promove a nebulizador. Outra vantagem do nebulizador é que ao líquido nele iniroduzido pode-se adicionar drogas capazes de: reduzir edema da traquéia, promover relaxamento muscular brônquico, aliviar espasmo e fluidificar secreções.

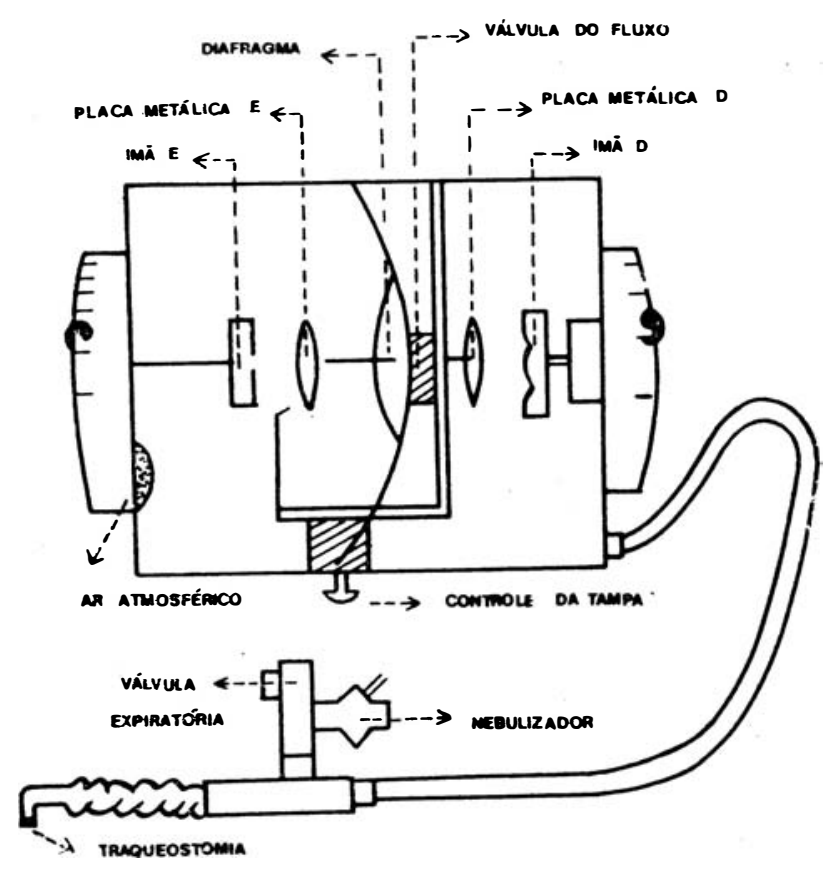

FIG. 1

Funcionamento do aparelho (Fig. 1): O funcionamento do aparelho exige uma fonte de energia que é representada pelo oxigênio ou ar sob pressão. 
Uma caixa pequena de plástico verde contém um conjunto de peças entre as quais destacam: algumas válvulas, duas placas metálicas, dois imãs e um diafragma elástico que divide internamente a caixa do aparelho em duas câmaras distintas (De E). Aos lados (D e E) do diafragma há uma placa metálica e um imã.

A força de atração magnética dos imãs, atuando sobre as placas metálicas, é a responsável pelo afastamento do diafragma para a direita ou para a esquerda provocando respectivamente a abertura e o fechamento da válvula do fluxo de gás. Isto ocorre porque estando o diafragma, as placas metálicas e a válvula do fluxo montados num eixo comum, o movimento de uma das peças faz movimentar as outras.

A câmara esquerda (câmara da sensibilidade) está em comunicação com o ar atmosférico através de um filtro de ar e, a câmara direita (câmara da pressão) com as vias respiratórias do paciente. Estando o aparelho em atividade, a pressão na câmara direita atinge o valor preajustado na máquina. A válvula do fluxo se mantém aberta durante a inspiração permitindo que os gazes sọb pressão entrem na câmara direita e em seguida passem para o paciente. Entretanto, a entrada gradual de gazes conduz a um aumento de pressão nesta câmara provocando o desvio do diafragma para o lado esquerdo; em outras palavras ele se afasta do imã direito e a placa metálica esquerda é empurrada em direção ao imã esquerdo. Com o desvio do diafragma para a esquerda, a válvula do fluxo se fecha, terminando assim a inspiração. Neste momento a máquina cicla.

A expiração é fassiva e os pulmões desinsuflam por sua própria elasticidade. Os gases expirados são eliminados por uma válvula expiratória, o esforço inspiratório do paciente faz com que na câmara esquerda a placa metálica se afaste do seu imã correspondente e piratória, que se mantém fechada durante a inspiração. Terminada a fase expiratória, o esforço inspirado do paciente faz com que na câmara esquerda a placa metálica se afaste do seu imã correspondente e em consequência a placa metálica direita e o diafragma também se movem para a direita. O imã direito, pela sua força de atração e lutando para se apossar da placa metálica direita, acaba deslocando o diafragma para a direita e em consequência abre-se a válvula do fluxo e repete-se a fase da inspiração.

Ao analisar o funcionamento da máquina acima descrito observa-se que a abertura e o fechamento da válvula do fluxo dependem da ação resultante de duas forças (pressão dos gases e pressão magnética) agindo em lados opostos do diafragma. 
Na Figura II, apresentamos um desenho esquemático da parte externa do Bird-Mark 7 com os respectivos controles a serem usados pelo operardor da máquina. Para iidentificá-los usaremos nas explicações que se seguem, os mesmos números enontrados na Fig. II.

Fig. II

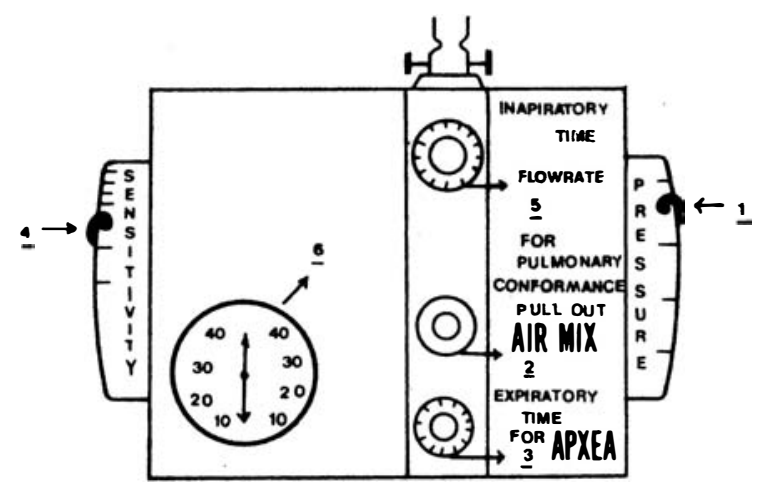

N.o 1 - Controle da Pressão (Cycling Pressure Control): Fazendo o dispositivo indicador da pressão caminhar sobre uma escala de valores de números de 5 a 40 o operador escolhe em $\mathrm{cm}$ de $\mathrm{H}_{2} \mathrm{O}$ a pressão que irá usar. Comumente são usadas as pressões de 10 a 25 e valores mais elevados podem interferir com o fluxo sanguíneo aos pulmōes. Quando alteramos o valor da pressão, o que estamos realmente fazendo dentro do aparelho, é a modificação da distância entre a placa metálica direita e o imã correspondente e, portanto, alterando a força magnética (*) entre eles. Sendo alta a pressão prefixada, o imã da câmara direita estará mais próximo da placa metálica direita; para superar a força magnética existente entre eles, há necessidade de uma pressão suficientemente alta na câmara direita, a fim de favorecer o deslocamento do diafragma para a esquerda e consequente fechamento da válvula do fluxo. Com pressōes mais elevadas o volume de ar insuflado nas vias aéreas será maior.

N.o 2 - Controle de entrada do ar atmosférico (Air-mix for pulmonary conformance): Quando se deseja diluir $\mathrm{o}_{\mathrm{O}_{2}}$ basta puxar para a frente o controle n.o 2 prendê-lo com 0 anel giratório, que o contorna, permitindo assim a entrada do ar ambiente; ne-

(*) A força de atração de um campo magnético sobre um ponto situado. à distância $\mathbf{X}$, é inversamente proporcional ao quadrado desta distância. 
cessitando usar $100 \%$ de $\mathrm{O}_{2}$ ele deverá sem empurrado para trás. Quando usamos $\quad 0 \quad \mathrm{O}_{2}$ diluído em ar atmosférico, 0 aparelho liberta uma mistura de $40 \%$ de oxigênio. Considerando-se entretanto que o paciente ainda recebe uma quantidade adicional de $\mathrm{O}_{2}$ pelo nebulizador, conclui-se que ele inspira uma mistura com teor bem mais elevado em $\mathrm{O}_{2}$.

A utilização de a atmosférico puro, ou de $\mathrm{O}_{2}$ puro ou diluído baseia-se no critério médico frente às condições do paciente e na avaliação das desvantagens da agressão de $\mathrm{O}_{2}$ sobre 0 sistema respiratório, quando esse gás é usado puro ou em misturas de alta concentração durante períodos longos. Isto poderia acarretar irritação e descamação da mucosa e outras alterações pulmonares.

N. 3 - Controle de Tempo expiratório (Rate control for apnea) : Em ventilação assistida não há preocupação em se graduar o controle n.o 3, puis a expiração é passiva. Quando se deseja desligar c controle de tempo basta fazê-lo girar em sentido horário.

Para o paciente apneico ou com movimentos respiratórios fracos necessitando de ventilação automática controlada, a duração da fase expiratória é regulada com o auxílio de tempo (n.o 3 ). Para isto basta fazê-lo girar em sentido anti-horário até que se consiga o tempo expiratório desejado. A frequência respiratória altera-se sob a influência do tempo expiratório e quanto mais curto ele for, maior será a frequência. São geralmente usadas as frequências de 10 a 16 respirações por minuto, podendo-se, baseando-se nos problemas dos pacientes, usar frequência mais rápidas.

N. 4 - Controle da sensibilidade do aparelho: Fazendo-se o dispositivo indicador da sensibilidade caminhar sobre uma escala de números (5 a 40), o operador gradua a sensibilidade do aparelho. Ela traduz o esforço inspiratório que o paciente deverá fazer para desencadear o ciclo respiratório pela abertura da válvula do fluxo. Quanto menor for o valor numérico escolhido para a sensibilidade tanto maior será a facilidade de abertura da válvula do fluxo para a mesma pressão positiva, o que equivale a dizer que o aparelho é sensível ao menor esforço do paciente.

Quando alteramos o valor numérico da sensibilidade, o que estamos realmente fazendo dentro do aparelho é a modificação da distância entre o imã e a placa da câmara esquerda e consequentemente alterando a força de atração magnética entre eles. $O$ valor da sensibilidade é obtido pela distância em que colocamos o imã e a placa metálica da câmara esquerda. A uma distância pequena correspondem: grande força de atração magnética, grande esforço inspiratório do paciente para iniciar o fluxo de gás e pe- 
quena sensibilidade.A uma distância grande correspondem: pequena força de atração magnética, pequeno esforço inspiratório do paciente para iniciar o fiuxo e grande sensibilidade.

N. 5 - Controle do fluxo de gás (Flowłrate-Inspiratory time) : Este botão de controle, que é circundado por uma escala de valores de números arbitrários (5 a 40) permite prefixar a velocidade do fluxo e alterar o tempo inspiratório. Com fluxos de números mais altos os tempos inspiratórios serão mais curtos porque os pulmões se insuflam em menor tempo. Note-se entretanto que o mesmo fluxo usado para pacientes diferentes não irá produzir o mesmo tempo inspiratório em todos eles. A relação entre fluxo e tempo inspiratório não depende exclusivamente do aparelho de outras condições inclusive grau de resistência das vias aéreas.

N.. 6 - Manômetro: Registra em $\mathrm{cm}$ de $\mathrm{H}_{2} \mathrm{O}$ o ponto máximo da pressão nas vias aéreas na insuflação de um certo volume corrente de gás.

Como regular o aparelho: O aparelho deve ser ajustado para satisfazer as necessidades individuais de cada paciente respeitando-se sempre, em qualquer arranjo escolhido, o princípio de que seja mantido um volume corrente útil.

Inicialmente deve-se escolher números baixos e iguais para a pressão, fluxo e sensibilidade (10 a 15). Estes números poderão ser gradualmente alterados até que se consiga um fluxo adequado para o paciente.

Ao manejar com o aparelho deve-se ter em mente que a alteração feita num dos controles requer ajustamento nos outros e que uma inspiração mais lenta, com pressão moderada, é geralmente mais eficaz do que uma inspiração rápida com alta pressão.

O respirador Bird sendo muito sensível, pode alterar seu funcionamento por inúmeras causas, inclusive mudança de posição do paciente no leito e acúmulo de secreções na árvore brônquica exigindo supervisão constante. A verificação de que o aparelho está realmente beneficiando o paciente deverá ser feita pelo controle de volume corrente em intervalos regulares, pela avaliação dos sinais clínicos e dosagem de gases no sangue arterial. Para maiores detalhes sobre a técnica e cuidados em ventilação artificial recomendamos os trabalhos de Saraiva e colaboradora (7-8), onde os autores baseando-se em experiências pessoais descrevem a conduta por eles usada.

\section{CUIDADOS DE ENFERMAGEM}

Segundo Nett, o sucesso no tratamento do paciente com insuficiência respiratória pelo emprego de um respirador, depende de um esquema de trabalho de grupo no qual se distinguem funções 
igualmente valiosas de médicos e enfermeiros. A instalação do aparelho, a dosagem de energia. verificação do volume corrente, as ordens para cuidados são da competência médica, porém, muitos detalhes do tratamento e cuidados aplicados são atividades da enfermagem.

Pela variedade de situações patológicas que requerem o uso da ventilação artificial assistida ou controlada é de se prever que também diferem muito as condições dos pacientes. Ora são pacientes conscientes, ora inconscientes, e ainda há os que mantêm atividade muscular ou que apresentam relaxamento muscular ou paralisias. Esta diversidade de condições isoladas ou associadas não permite estabelecer um plano rígido de cuidados de enfermagem exigindo cada paciente uma avaliação e um planejamento específico.

De ræodo geral, como funções de enfermeira poderão ser lembrados os seguintes cuidados:

1. Controle dos sinais vitais e observação de sintomas principalmente os que se referem à falta de oxigenação adequada: cianose, inquietação.

2. Manter o fluxo de oxigênio verificando com frequência se o cilindro de gás não está esgotado ou se não houve interrupção nủ fornecimento proveniente das canalizações da parede. Um cilindro cheio de $\mathrm{O}_{2}$ deve estar preparado para emergência ou substituição.

3. Cỏservação do funcionamento da máquina. Esta observação constante é essencial pois uma falha no funcionamento pode resultar em hipóxia. O ruído característico da máquina indica que ela está trabalhando, porém, apenas por ouví-lo, não podemos ter a certeza de que o paciente está sendo ventilado. Devemos estar vigilantes a fim de evitar ou corrigir as seguintes ocorrências: traquéia do aparelho mal adaptada à traqueostomia, dobras ou obstruções dos tubos. Estas, quando presentes. interrompem a ventilação sem contudo sustar o trabalho da máquina. Manter em reservas um ou mais respiradores sobressalentes em boas condições de funcionamento é também aconselhável para os casos de substituição de aparelhos com defeitos.

4. Assistência psicológica: ser submetido a um tratamento com o auxílio do Bird é uma experiência nova para o paciente e segundo McCallum $\mathrm{H}$ é "cansativa e exaustiva". A enfermeira com sua presença constante deve procurar tranquili- 
zá-lo fazendo com que ele encontre um ambiente de segurança ao perceber que ela está sempre atenta ao seu lado, observando-o providenciando tudo o que lhe for necessário. Todos os tratamentos devem ser cuidadosamente explicados antes de sua execução numa tentativa de aliviar a sua ansiedade.

Como parte da assistência psicológica, é de suma importância estabelecer um método de comunicação entre enfermeira e paciente quando este pelo fato de estar com traqueostomia ligada ao Bird não pode falar normalmente. Para aliviar essa deficiência são sugeridos os seguintes recursos: manter campainha próxima ao leito, fornecer prancha com papel e lápis para o paciente escrever, e ainda procurar entendê-lo pela mímica e movimentos dos lábios.

5. Manter o nebulizador com o líquido prescrito pelo médico (água destilada, soro fisiológico, medicamentos) e verificar se a nebulização está se processando normalmente.

6. Aspirar secreçōes: Um aspirador de secreçōes e catéteres estéreis devem ser mantidos próximos ao leito. A aspiração de secreções, via traqueostomia, deve ser executada pela enfermeira tantas vezes quantas necessárias mantendo com rigor as normas de assepsia para a profilaxia das infecçōes pulmonares. As exigências mínimas para esta profilaxia são: mãos limpas; uso de luvas; de preferência usar catéteres sem orifícios laterais para evitar traumatizar a traquéia; usar um catéter estéril para cada aspiração; executar uma sucção meticulosa, assética e atraumática.

7. Instruir o paciente, quando consciente, a sincronizar a respiração com o ritmo do respirador. Se ele se agita e luta contra a máquina é provável que ela não esteja bem regulada; o médico responsável deverá ser solicitado para fazer a regulagem necessária.

8. Alimentação: Quando a via oral não pode ser usada pela presença de distúrbios da deglutição, o que aliás é bastante frequente em pacientes com ventilação artificial, compete à enfermeira manter, segundo prescrição médica, a hidratação por via parenteral, ou alimentação por sonda, observando em cada caso os cuidados específicos.

9. Cuidados gerais de higiene, movimentação frequente, boa posição no leito, visando o conforto do paciente, prevenção de escaras e deformidades. 


\section{REFERENCIAS BIBLIOGRAFICAS}

1. COOPER, PHILIP - Ward procedures and techniques. New York, Appleton, 1967. p. 222-229.

2. FELL, A. V. - The bird respirator in cardiothoracic surgery. Nursing Times, 60 (2): 652-653. may 22, 1964.

3. HUNTER, A. R. - Essentials of artificial ventilation of the lungs. London, Churchill, p. 9-224, 1962.

4. LANE, J. C. - Insuficiência respiratória aguda. Revista Paulista de Medicina, 67 (6) : 321-333. dez. 1965.

5. McCALLUM, H. - Caring for patients with respiratory problems. The Canadian Nurses, 61 (12): 958-961, dec. 1965.

6. NETT, L. and PETTY, T. L. - Acute respiratory faillure: principles of care. The American Journal of Nursing, 67 (9): 1847-1953, sep., 1967.

7. SARAIVA, P.A.P. - Uso clínico de respiradores mecânicos. Revista Brasileira de Anestesiologia, 18 (1): 45-49, jan/mar., 1968.

8. SARAIVA, P.A.P. [e] ABREU, M.J.D. - Assistência ventilatória prolongada A Fôlha Médica. 55 (1): 139-144, jul., 1967.

'9. SECHZER, P. - The bird respirator. New York, Altneu, 1965. p. 7-42. 